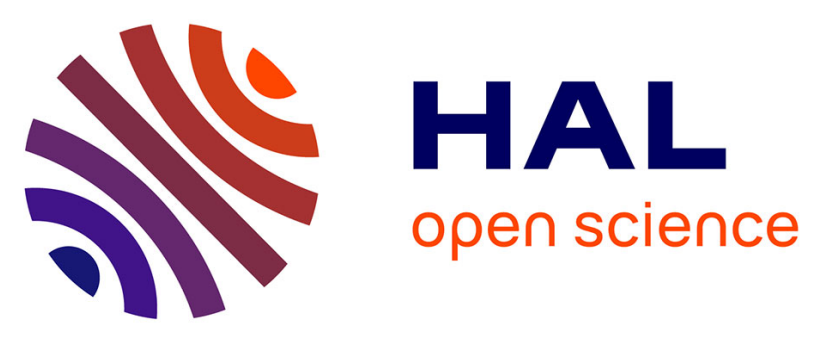

\title{
More sustainable European diets based on self-selection do not require exclusion of entire categories of food
}

Florent Vieux, Lisa Privet, Louis Georges Soler, Xavier Irz, Marika Ferrari, Stefania Sette, Susanna Raulio, Heli Tapanainen, Ruben Hoffmann, Yves Surry, et al.

\section{To cite this version:}

Florent Vieux, Lisa Privet, Louis Georges Soler, Xavier Irz, Marika Ferrari, et al.. More sustainable European diets based on self-selection do not require exclusion of entire categories of food. Journal of Cleaner Production, 2020, 248, pp.1-10. 10.1016/j.jclepro.2019.119298 . hal-02628169

\section{HAL Id: hal-02628169 \\ https://hal.inrae.fr/hal-02628169}

Submitted on 26 May 2020

HAL is a multi-disciplinary open access archive for the deposit and dissemination of scientific research documents, whether they are published or not. The documents may come from teaching and research institutions in France or abroad, or from public or private research centers.
L'archive ouverte pluridisciplinaire HAL, est destinée au dépôt et à la diffusion de documents scientifiques de niveau recherche, publiés ou non, émanant des établissements d'enseignement et de recherche français ou étrangers, des laboratoires publics ou privés.

\section{(1) (1) $\$$}

Distributed under a Creative Commons Attribution - NonCommercial - NoDerivatives| 4.0 
2 Title: More sustainable European diets based on self-selection do not require exclusion of entire

3 categories of food

4

5 Abbreviations:

6 AHC: agglomerative hierarchical clustering

7 ANOVA: Analysis of variance

8 EFSA: European Food Safety Authority

9 FAO: Food and Agriculture Organization of the United Nations

10 FINDIET: Finnish national dietary survey

11 FOODEX: Food classification system derived by the EFSA

12 GHGE: greenhouse gas emissions

13 INCA2: second French Individual and National Dietary Survey

14 INRAN-SCAI: Italian National Food consumption survey

15 LCA: life cycle assessment

16 MAR: Mean Adequacy Ratio

17 MER: Mean Excess Ratio

18 MFA: multiple factorial analysis

19 NDNS: United Kingdom national diet and nutrition survey

20 RIKSMATEN: Swedish national dietary survey

21 SED: solid energy density

22 Kcal: kilocalories

23 g=grams

24 d=day 


\section{Abstract}

Sustainable diets are nutritious, culturally acceptable and have low environmental impact. The aim of this study was to identify sustainable diets among actual self-selected diets based on five national dietary surveys (Finland, France, Italy, Sweden, the United Kingdom), without ex ante assumptions concerning the food content of diets. Using nutrient intakes and dietary greenhouse gas emissions as active variables, energy-adjusted multiple factor analysis and agglomerative hierarchical clustering were applied to identify clusters of diets. The cluster with the lowest dietary GHGE had the lowest nutritional quality. Another cluster displayed a good compromise between nutritional quality and dietary GHGE (21\% lower than the average of observed diets) and was therefore considered as more sustainable than the other clusters. Compared to the rest of the sample, diets in the more sustainable cluster were characterized by a larger quantity of plant-based products and lower quantities of meats, soft drinks and alcoholic beverages. The average diet in this cluster contained approximately 1000 grams per day $(\mathrm{g} / \mathrm{d}$ ) of plant-based products (including $400 \mathrm{~g} / \mathrm{d}$ of fruit and vegetables, $100 \mathrm{~g} / \mathrm{d}$ of juices and $500 \mathrm{~g} / \mathrm{d}$ of other plants) and $400 \mathrm{~g} / \mathrm{d}$ of animal-based products (including $100 \mathrm{~g} / \mathrm{d}$ of meat/fish/eggs of which livestock meat represented $20 \mathrm{~g} / \mathrm{d}$, $50 \mathrm{~g} / \mathrm{d}$ of animal-based composite dishes, $30 \mathrm{~g} / \mathrm{d}$ of cheese and $220 \mathrm{~g} / \mathrm{d}$ of other dairy products). We concluded that exclusion of entire food categories (e.g., meat) is not necessary to improve the sustainability of European diets.

Keywords: Nutrition, greenhouse gas emissions, multicriteria analysis, meat, environment, flexitarian

\section{Highlights:}

Self-selected diets were studied because they are likely to be culturally acceptable.

European diets with the best environmental and nutritional compromise were identified.

The greenhouse gas emissions were $21 \%$ lower than the average of observed diets.

The diets contained $1 \mathrm{~kg}$ of plant-based products and $400 \mathrm{~g}$ of animal-based products.

Exclusion of entire categories of food is not a necessity to improve sustainability. 


\section{Introduction}

In response to the growing evidence that food consumption patterns, due to negative health and environmental impacts, are fundamentally unsustainable globally the Food and Agriculture Organization of the United Nations (FAO) defined sustainable diets as environmentally respectful, nutritionally adequate and healthy, economically fair and affordable and culturally acceptable (FAO, 2010). In the process of establishing the food content of such diets, the compatibility between environmental impact and healthiness has received increasing attention, especially in European countries (Aleksandrowicz et al., 2016; Mertens et al., 2017; Perignon et al., 2017). Most studies are based on comparisons between current and theoretical diets (Aleksandrowicz et al., 2016; Mertens et al., 2017; Nelson et al., 2016), with the latter derived based on either simulations or mathematical optimization. Simulations have included scenarios based on adherence to dietary guidelines (Tukker et al., 2011; Wolf et al., 2011), traditional food patterns (e.g. Mediterranean, Nordic) (SáezAlmendros et al., 2013; Saxe et al., 2012; Tukker et al., 2011), exclusion of entire food categories (e.g. pescatarian, vegetarian, vegan diets) (Baroni et al., 2007; Berners-Lee et al., 2012; Kim et al., 2019; Springmann et al., 2018; Tilman and Clark, 2014), and replacement of specific food items (e.g. meat/dairy being replaced by plant-based products) (Seves et al., 2017; Temme et al., 2013; van de Kamp et al., 2018a, 2018b; Vieux et al., 2012). A limitation of simulation studies is that they are based on preconceived views concerning the food content of a sustainable diet. Another limitation is that nutritional and environmental indicators are outputs of the scenarios, meaning that they do not necessarily improve and may even worsen in some scenarios (Payne et al., 2016; Seves et al., 2017; Vieux et al., 2012). In contrast, mathematical optimization integrates nutritional and environmental constraints in the model thereby guaranteeing that the diets modeled are both nutritionally adequate and reduce environmental impacts (Donati et al., 2016; Green et al., 2015; Horgan et al., 2016; Macdiarmid et al., 2012a; Perignon et al., 2016b; van Dooren et al., 2015; Vieux et al., 2018). By deriving optimized diets which are as close as possible to observed population averages (Macdiarmid et al., 2012b; Perignon et al., 2016b) or individual diets (Horgan et al., 2016) the cultural dimension is taken into account. However, the findings remain theoretical as the modeled diets are never tested in the real word and hence it is questionable whether consumers would accept these diets. 
Thus, there is a need to more directly take into account the notion of cultural acceptability and consumer preferences (Irz et al., 2016). It seems reasonable to assume that self-selected diets are more culturally appropriate than theoretical diets as, by definition, they are already consumed by at least some individuals (Aleksandrowicz et al., 2016; Perignon et al., 2017). However, epidemiological studies analyzing the sustainability of self-selected diets have found that lower greenhouse gas emissions (GHGE) are not necessarily associated with higher nutritional quality and vice versa (Biesbroek et al., 2017; Payne et al., 2016; Perignon et al., 2016a; Sjors et al., 2017; Vieux et al., 2013a). Investigating the impact of dietary recommendations based on a behavioral consumer choice model (Irz et al., 2016) reached a similar conclusion. This can be explained by a quantity vs quality dichotomy, with the environmental impact being closely and positively linked to both physical quantities and calories ingested (Vieux et al., 2012). At a given level of caloric intake, low quality diets, due to high energy density, are consumed in smaller quantities and thus often have low GHGE (Vieux et al., 2013a). Furthermore, some foods, such as high-sugar foods and refined cereals, display both low GHGE and low nutritional quality (Masset et al., 2014a; Payne et al., 2016). As sustainability dimensions may not be compatible with one another, one-dimensional analyses are inappropriate in identifying more sustainable food choices.

Multicriteria analyses applied to self-selected diets, overcoming the quantity vs quality dichotomy, are urgently needed in order to identify realistic sustainable diets that are culturally acceptable. The objective of the present study was therefore to apply such energyadjusted multicriteria approaches, without ex ante assumptions concerning the food content, to identify which current self-selected diets are relatively more sustainable in five European countries, namely Finland, France, Italy, Sweden and the UK. Our contribution is both methodological and empirical. We develop and test a new method for identification of sustainable diets and the results have broad policy implications. We conclude that significantly lower GHGE from diets with high nutritional quality and already adopted by a large share of the European population is possible. The relatively more sustainable diets do not exclude entire categories of foods (e.g. meat), which suggests that flexitarian diets should be promoted in order to improve the sustainability of European diets. 


\section{Material and Methods}

\subsection{Dietary surveys and nutritional and environmental indicators}

\subsubsection{Study population}

Dietary intake data were derived from five national food consumption surveys, i.e. the Finnish 2012 national dietary survey (FINDIET) based on one 48h recall ( $n=1708)$ (Helldan et al., 2013); the French 2006-2007 individual and national dietary survey (INCA2) based on 7-day dietary records ( $n=4079$ ) (AFSSA, 2009); the Italian 2005-2006 national food consumption survey (INRAN-SCAI) based on 3-day dietary records ( $n=3323$ ) (Leclercq et al., 2009); the Swedish 2010 national dietary survey (Riksmaten) based on 4-day dietary records ( $n=1797$ ) (Amcoff et al., 2012); and the 2008-2012 rolling national diet and nutrition survey (NDNS) in the UK based on 4-day dietary records ( $n=4156$ ) (NatCen Social Research et al., 2015). Detailed information of each survey is available in supplementary data. Individuals younger than 18 years old and older than 64 years old, consumers of dietary supplements and one outlier (Franklin et al., 2001) were excluded. The final sample consisted of 8302 individuals including 568 men and 679 women in Finland, 930 men and 1323 women in France, 967 men and 1105 women in Italy, 588 men and 764 women in Sweden and, 627 men and 751 women in the UK. Age, and socio-demographics information of each selected sample are available in supplementary data.

\subsubsection{Individual dietary intakes}

Each national institute provided individual energy and nutrient intakes as well as the consumed quantities of 151 food items. The food items were derived from the FoodEx food classification system (European Food Safety Authority, 2011) and grouped into 6 food groups and 27 food sub-groups. Information on folates was not available in the Italian survey and was assumed to be the same as for the corresponding French food items (The French Information Center on Food Quality, 2013). Information on free sugars (monosaccharides and disaccharides added to foods by the manufacturer, cook or consumer, plus the sugars that are naturally present in honey, syrups and fruit juices) was not available in the Swedish, Finish and Italian surveys. It was assumed that the content of intrinsic sugar (naturally present in food) was the same as for the corresponding French food items (Lluch et al., 2017) and the level of free sugars was calculated as the difference between total sugar content (according to the national surveys) and intrinsic sugar content.

\subsubsection{Nutritional quality indicators}


Three nutritional quality indicators (Vieux et al., 2013b) were estimated for each individual: The Mean Adequacy Ratio (MAR), the Mean Excess Ratio (MER) and the Solid Energy Density (SED). Briefly, the MAR was calculated for the diet of each individual as the mean percentage of European Food Safety Authority (EFSA) dietary reference values (European Food Safety Authority, n.d.) for 17 beneficial nutrients. It was used as an indicator of good nutritional quality and varied between 0 (low quality) and 100 (high quality) with a daily intake of each nutrient higher than the dietary reference value capped at 100 . The MER was similarly constructed but included nutrients to be restricted (sodium, free sugars, saturated fatty acids). It was used as an indicator of poor nutritional quality with a minimum value of 100 when none of the nutrients exceeded the maximum recommended value in the diet. SED, calculated as the energy from solid foods (all food groups except hot drinks, sugary and non-sugary beverages, milk, juices, water, alcohol) divided by the quantity provided by solid foods, was used as another indicator of poor nutritional quality as lower SED is recommended by several public health authorities (World Cancer Research/American Institute for Cancer Research, 2007; World Health Organization, 2003) to prevent obesity and obesity-related diseases (Ledikwe et al., 2006).

\subsubsection{GHGE associated with food consumption}

A GHGE coefficient, expressed in grams of $\mathrm{CO}_{2}$ equivalents ( $\left.\mathrm{C}_{2} \mathrm{eq}\right)$, derived from life cycle assessment (LCA) literature studies was assigned to each of the 151 food items as described by Hartikainen and Pulkkinen (Hartikainen and Pulkkinen, 2016). The reader should be aware that there are major uncertainties related to GHGE coefficients aggregated from the LCA literature (Clune et al., 2017; Kendall and Chang, 2009) but that it is still the best available alternative. For each individual, the consumption of 151 food items was matched to their respective GHGE in order to calculate dietary GHGE, i.e. the GHGE related to the daily food consumption of the individual. Dietary GHGE were used as indicators of the environmental impacts of diets.

\subsection{Identification of "More-Sustainable" cluster and class}

We hypothesized that some diets combine cultural acceptability (because they are selfselected), good nutritional quality and low environmental impact. Diets that relative to other diets were more sustainable were identified using two approaches: a new clustering approach 
181

182

183

184

185

186

187

188

189

190

191

192

193

194

195

196

197

198

199

200

201

202

203

204

205

206

207

208

209

210

211

specifically developed for this study (described in 2.2.1) and a previously described classification approach (Masset et al., 2014b). The methods were used to identify a collection of self-selected diets called the "More-Sustainable" cluster and the "More-Sustainable" class, respectively.

Both approaches were applied without ex ante assumptions concerning the food content of sustainable diets. Adjustments were made for energy intakes to take into account the welldocumented and strongly positive relationship between dietary GHGE and energy intakes (Monsivais et al., 2015; Saxe et al., 2012; Vieux et al., 2012).

\subsubsection{Clustering of diets and identification of the "More-Sustainable" cluster}

The "More-Sustainable" cluster was identified as the cluster with the best compromise between high nutritional quality and low dietary GHGE. Clustering was conducted in two consecutive steps. In a first step, multiple factorial analysis (MFA) (Tucker, 2010) was applied to the 8302 individual diets, using nutrient intakes (representing the nutritional dimension) and dietary GHGE (representing the environmental dimension) as active variables and intake by food sub-group, diet quality indicators (SED, MAR and MER), number of food items consumed and other characteristics (total energy, total quantity, age) as illustrative variables.

The illustrative variables are useful in interpreting the results but do not influence the principal component analysis. Because the environmental dimension was represented by only one variable while the nutritional dimension included 28 nutrients, dietary GHGE were weighted to be as important as nutritional intakes. All variables included in the MFA were adjusted for total energy intake (using residuals of each linear regression between the variable considered and the total energy intake) and scaled to the standard deviation in order to avoid bias due to different units. In a second step, a partition of diets was carried out by agglomerative hierarchical clustering $(\mathrm{AHC})$ using Euclidean distances between individuals, based on their coordinates on the first component, i.e. the new variables derived by the MFA which summarize the largest variability of the raw data (Contreras and Murtagh, 2015; Cornillon et al., 2012). Individuals were in this second step grouped into clusters. The number of clusters was chosen using two criteria: the gain of inter/intra cluster inertia ratio and the interpretability of clusters. Comparisons of characteristics across clusters, especially regarding dietary GHGE and nutritional quality indicators, were used to name clusters and to identify which of the clusters defined by AHC that was the "More-Sustainable". 
The approach used to identify a class of more sustainable diets was based on the methodology suggested by Masset et al (Masset et al., 2014b). Briefly, this approach was used to define individual diets as belonging to "More-Sustainable" class if the diet had a MAR above, a MER below, and dietary GHGE (all being adjusted for energy) below the energy-adjusted genderspecific median.

\subsection{Statistical analysis}

Correlations between the first two components from the MFA and the active and illustrative variables were computed and represented on a correlation circle. Each cluster was described in terms of individual characteristics (nationality, gender, age) and diet characteristics. Differences of means between clusters were tested by analysis of variance (ANOVA) adjusted as appropriate (Fisher, 1925). Post-hoc comparisons between means using Tukey correction were performed. Differences in the distribution of nationalities across the different clusters were analyzed with a chi-squared test. The "More-Sustainable" cluster was isolated and nutritional intakes as well as consumption (in percentage of total diet weight) of food groups and sub-groups were compared to the rest of the sample by ANOVA after adjusting for total energy intake. The "More-Sustainable" class was similarly compared to the rest of the sample. This made it possible to qualitatively identify the main differences between the "MoreSustainable" cluster and the "More-Sustainable" class. Statistical softwares SAS version 9.4 (SAS Institute, Cary, NC, USA) and R version 3.3.0 (Base

233 and FactoMineR packages) were used to perform the statistical analysis. A $5 \%$ level of statistical significance was used for all tests. 


\section{3. Results}

236 The two first components of the MFA accounted for $23 \%$ and $15 \%$ of the variability (Figure 1 ).

237 The MFA showed that dietary GHGE were inversely correlated with carbohydrates and sugar 238 intakes, including free sugars (Figure 1, panel A). Vitamins and minerals were highly correlated 239 with each other but not with dietary GHGE. Graphically representing consumption of food 240 groups in the map defined by MFA (Figure 1, panel B) revealed that consumption of livestock 241 meat was strongly correlated with dietary GHGE while consumption of fruits and vegetables 242 as well as dairy were positively correlated with vitamins and minerals. 


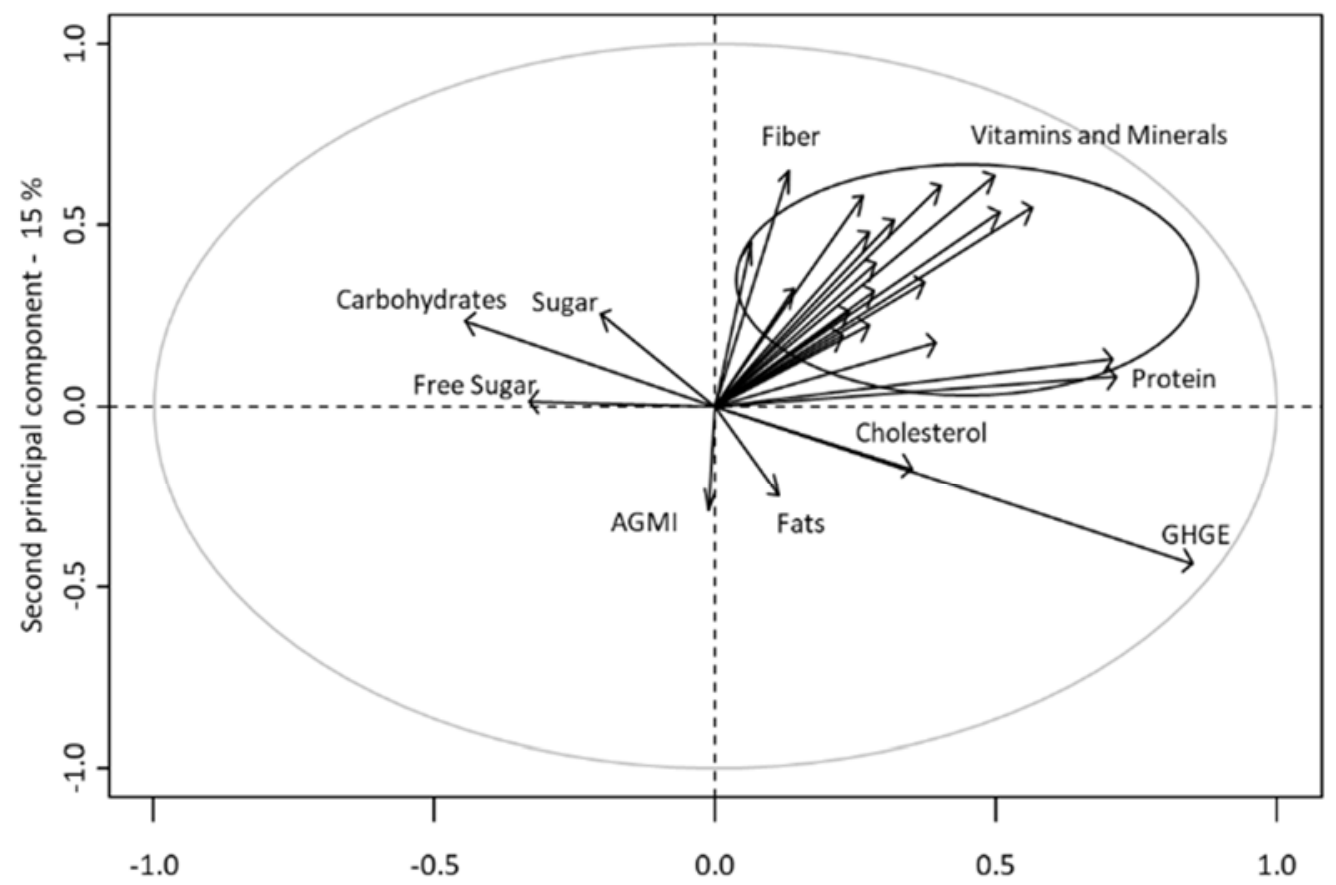

PANEL B: Illustrative variables ${ }^{1}$

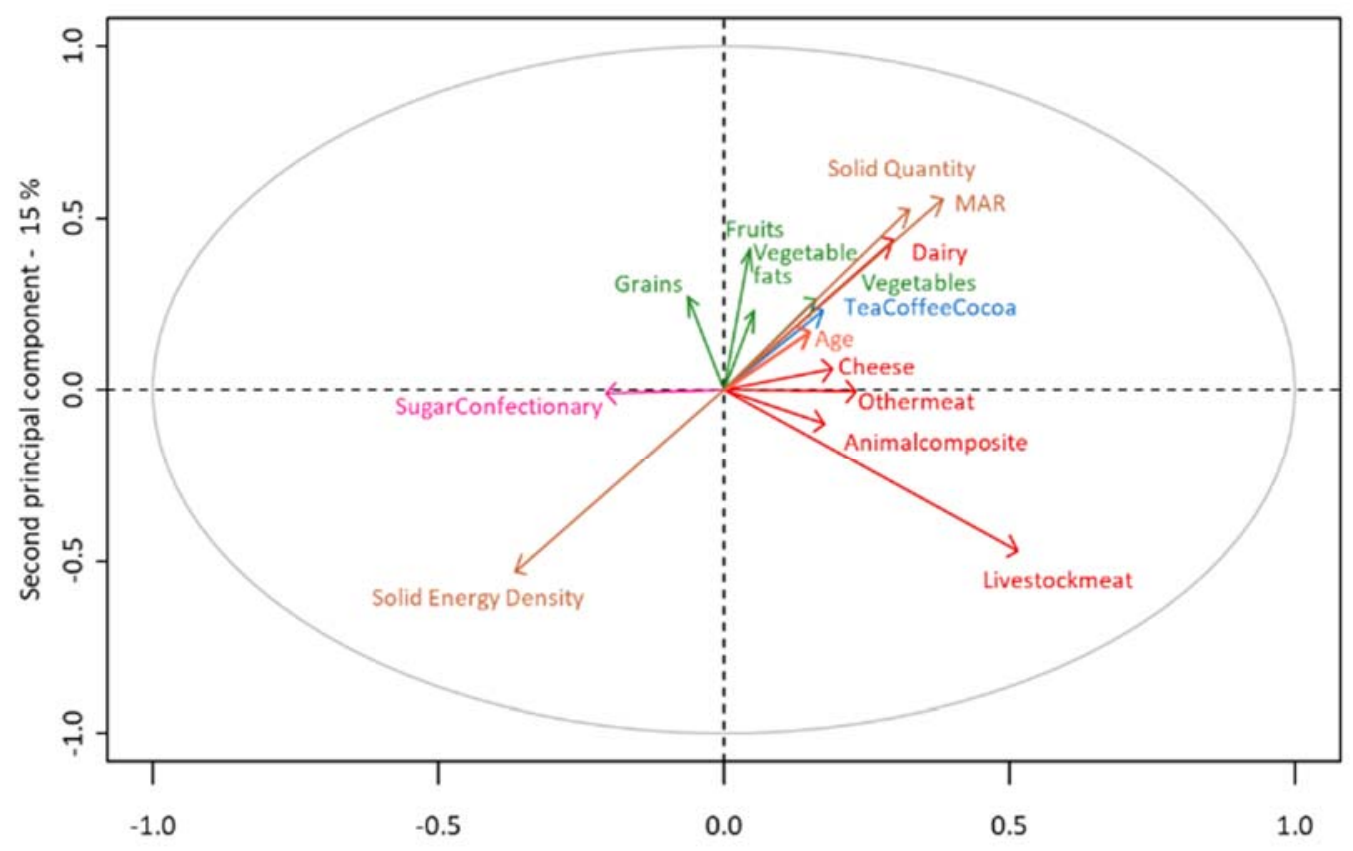

$250{ }^{1}$ Only illustrative variables with an Euclidean distance from the center higher than 0.05 were represented. 
Individuals were grouped into six clusters by applying hierarchical clustering and studying the inertia gain and the interpretability of clusters. The characteristics of the overall sample and the six clusters are shown in Table 1. Mean energy intake varied from 1916 kilocalories (kcal) per day, in cluster 3, to $2152 \mathrm{kcal}$ per day, in cluster 4 . Cluster 1 had the lowest dietary GHGE (3551 $\mathrm{g} \mathrm{CO}_{2} \mathrm{eq} / \mathrm{d}$ ) and low nutritional quality, as indicated by the highest SED (191 kcal/100g), the lowest MAR (77\%) and the second highest MER (133\%). It was also characterized by the lowest mean age. Cluster 5 had the highest dietary GHGE (7034 g CO $\mathrm{CO}_{2} \mathrm{eq} / \mathrm{d}$ ) and nutritional quality similar to the overall sample average. Clusters 4 and 6 also had high dietary GHGE (>5000 $\left.\mathrm{g} \mathrm{CO}_{2} \mathrm{eq} / \mathrm{d}\right)$. Cluster 4 was characterized by the lowest SED (141 kcal/100g) and the highest MAR (93\%) but the highest MER (140\%). Cluster 6 was the smallest cluster $(<1 \%$ of the sample) and had the highest mean age. Cluster 3, representing 33\% of the whole sample, had intermediate dietary GHGE (4327 $\mathrm{g} \mathrm{CO}_{2} \mathrm{eq} / \mathrm{d}$ ) but the second lowest MAR (80 \%). Finally, cluster 2 , representing $18 \%$ of the sample, displayed the second lowest dietary GHGE (3834 g $\mathrm{CO}_{2} \mathrm{eq} / \mathrm{d}, 21 \%$ less than the sample average), the lowest MER (121\%), the second lowest SED (143 kcal/100g), and its MAR was relatively high (88\%). This cluster was therefore considered to be relatively more sustainable because none of the other clusters featured a better combination of low dietary GHGE and high nutritional quality. Names were also attributed to the other clusters according to their main specific characteristics. The percentage of individuals belonging to the "More-sustainable" cluster was $25.1 \%$ in Finland, $11.6 \%$ in France, $16.6 \%$ in Italy, $19.7 \%$ in Sweden and $23.4 \%$ in the UK (data not shown). 
$\underline{\text { Table } 1 . \text { Characteristics of the overall sample and the six clusters }{ }^{1}}$

\begin{tabular}{|c|c|c|c|c|c|c|c|}
\hline & All & Cluster 1 & Cluster 2 & Cluster 3 & Cluster 4 & Cluster 5 & Cluster 6 \\
\hline N (\%) & 8302 & $2020(24.33 \%)$ & $1498(18.04 \%)$ & 2749 (33.11\%) & 809 (9.74\%) & 1151 (13.86\%) & 75 (0.90\%) \\
\hline Age (y) & $42.57(12.77)$ & 38.51 (12.94) & $45.78(12.21)^{a}$ & $42.55(12.52)^{b}$ & $46.29(11.63)^{a}$ & $42.53(12.50)^{b}$ & $48.72(11.47)^{\mathrm{a}}$ \\
\hline Women (\%) & $55.67 \%$ & $57.77 \%$ & $61.95 \%$ & $58.86 \%$ & $49.32 \%$ & $41.18 \%$ & $48.00 \%$ \\
\hline Energy (kcal/d) & $2003.91(634.4)$ & $2059(680.4)^{a}$ & $1939(579.1)^{b}$ & $1916(599.3)^{b}$ & $2152(659.2)^{c}$ & $2091(638.5)^{\mathrm{ac}}$ & $2084(697.3)^{a b c}$ \\
\hline $\begin{array}{l}\text { Energy from solid } \\
\text { foods }{ }^{2}\end{array}$ & 1797 (579.6) & $1827(636.5)^{a}$ & $1742(532.3)^{b}$ & $1752(547.0)^{b}$ & $1900(594.9)^{c}$ & $1851(577.0)^{\mathrm{ac}}$ & $1868(653.4)^{\mathrm{abc}}$ \\
\hline Total quantity $(g / d)$ & $2587.80(878.5)$ & $2352(800.6)^{a}$ & $2886(783.0)^{b}$ & $2327(790.2)^{a}$ & 3359 (837.8) & $2676(882.2)^{c}$ & $2876(1076)^{b c}$ \\
\hline Solid quantity & $1083(349.7)$ & $969.0(326.2)^{a}$ & $1236(339.1)^{b}$ & $984.1(282.3)^{a}$ & 1375 (388.3) & $1109(320.0)^{c}$ & $1202(380.8)^{b c}$ \\
\hline GHGE (g CO2 eq/d) & 4516 (1789) & 3551 (1315) & 3834 (1188) & $4327(1254)$ & $5187(1538)^{a}$ & 7034 (1891) & $5191(1794)^{a}$ \\
\hline SED (kcal/100g) & $170.3(380.0)$ & $191.0(360.0)$ & $142.8(310.0)^{\mathrm{a}}$ & $179.4(320.0)$ & $140.9(320.0)^{a}$ & $169.2(330.0)^{b}$ & $158.8(380.0)^{b}$ \\
\hline MAR (\%) & $82.84(12.37)$ & 77.36 (13.89) & $88.55(8.04)^{a}$ & $79.92(12.34)$ & $93.02(5.49)^{b}$ & $84.34(9.91)$ & $90.37(7.08)^{\mathrm{ab}}$ \\
\hline MER (\%) & $128.08(33.01)$ & $132.74(36.96)^{a}$ & $121.42(28.27)^{b}$ & $124.43(28.9)^{c}$ & $139.7(39.68)^{d}$ & $129.0(32.14)^{\mathrm{e}}$ & $128.99(32.43)^{\text {abcde }}$ \\
\hline $\begin{array}{l}\text { Distinguishing } \\
\text { features } \\
\text { of cluster }\end{array}$ & & $\begin{array}{c}\text { Lowest GHGE, } \\
\text { Highest SED } \\
\text { Lowest MAR, } \\
2^{\text {nd }} \text { highest MER }\end{array}$ & $\begin{array}{l}2^{\text {nd }} \text { lowest GHGE } \\
2^{\text {nd }} \text { lowest SED } \\
\text { High MAR }(88 \%) \\
\text { Lowest MER }\end{array}$ & $2^{\text {nd }}$ lowest MAR & $\begin{array}{l}\text { Lowest SED } \\
\text { Highest MAR } \\
\text { Highest MER }\end{array}$ & Highest GHGE & $\begin{array}{l}\text { Highest intakes } \\
\text { of offals* }\end{array}$ \\
\hline Cluster Name & & «Lowest-GHGE» & «More-Sustainable» & «Smallest-Quantity» & "Largest-Quantity» & «Highest-GHGE» & "Others» \\
\hline
\end{tabular}

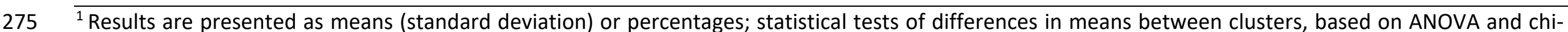

276 square, were all statistically significant $(p<0.01)$.

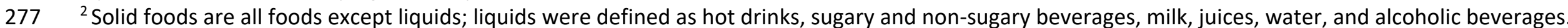

$278 \mathrm{a}, \mathrm{b}, \mathrm{c}, \mathrm{d}, \mathrm{e}$ Non-significant 2 by 2 post-hoc comparisons (using Tukey correction) have the same letter.

$279 *$ This cluster was characterized by the highest mean intake of Offals/Other meats (see table 2). 
The "Highest-GHGE" cluster (Cluster 5) was characterized by a high intake of livestock meat, animal fats and alcoholic beverages and low intakes of meat imitates, vegetable fats and plantbased composite dishes (Table 2). The "Lowest-GHGE" cluster (Cluster 1) had the highest consumption of soft drinks, sugar/confectionaries, and snack/desserts. The "Others" cluster (Cluster 6) was characterized by high intakes of offal/other meats.

The diets in the "More-Sustainable" cluster included all food groups and sub-groups. The cluster was characterized by a high consumption of fruits, vegetables, legumes/nuts/oilseeds, juices, and a low consumption of alcoholic beverages, animal-based composite dishes and animal fats. Furthermore, it contained more animal-products imitates than in other clusters although quantities remained small ( $<11 \mathrm{~g} / \mathrm{d}$ of meat and milk products imitates).

The diets in the cluster on average contained approximately $1000 \mathrm{~g} / \mathrm{d}$ of plant-based products including $400 \mathrm{~g} / \mathrm{d}$ of fruit and vegetables, $100 \mathrm{~g} / \mathrm{d}$ of juices and $500 \mathrm{~g} / \mathrm{d}$ of other plant-based products (such as $200 \mathrm{~g} / \mathrm{d}$ of composite dishes and $20 \mathrm{~g} / \mathrm{d}$ of legumes/nuts/oilseeds). Furthermore, they contained approximately $400 \mathrm{~g} / \mathrm{d}$ of animal-based products including 100 $\mathrm{g} / \mathrm{d}$ of meat/fish/eggs of which $20 \mathrm{~g} / \mathrm{d}$ was livestock-meat, $50 \mathrm{~g} / \mathrm{d}$ of composite dishes and 250 $\mathrm{g} / \mathrm{d}$ of dairy products of which $30 \mathrm{~g} / \mathrm{d}$ was cheese.

Figure 2 compares the "More-Sustainable" cluster to the rest of the sample. Individuals from the cluster consumed a larger total quantity which can be explained by the relatively low energy density of plant foods representing half of the quantity consumed (Figure 2 panel A). Among drinks (Figure 2 panel B), alcoholic beverages and soft drinks were the only sub-groups consumed in smaller quantities than in the rest of the sample. 


\begin{tabular}{|c|c|c|c|c|c|c|c|}
\hline & All & "Lowest-GHGE" & $\begin{array}{c}\text { "More- } \\
\text { Sustainable" }\end{array}$ & $\begin{array}{l}\text { "Smallest- } \\
\text { Quantity" }\end{array}$ & $\begin{array}{l}\text { "Largest- } \\
\text { Quantity" }\end{array}$ & $\begin{array}{l}\text { "Highest- } \\
\text { GHGE" }\end{array}$ & "Others" \\
\hline Grains & $209.83(119.0)$ & $221.97(117.85)$ & $229.27(122.7)$ & $182.02(96.29)$ & 259.67 (156.6) & $194.97(115.0)$ & 204.55 (126.7) \\
\hline Vegetables & $102.29(91.55)$ & 77.49 (71.74) & $146.11(113.2)$ & $88.77(71.4)$ & $119.45(108.0)$ & 106.88 (93.62) & $134.57(142.6)$ \\
\hline Legumes/Nuts/Oilseeds & $16.16(28.4)$ & $15.20(27.79)$ & $20.90(35.13)$ & $13.71(22.86)$ & $12.83(29.26)$ & $19.68(29.87)$ & $18.92(27.83)$ \\
\hline Fruits & $142.60(142.7)$ & $117.69(116.7)$ & 238.66 (180.4) & $105.27(97.61)$ & $185.83(175.3)$ & $118.02(125.8)$ & $173.77(180.1)$ \\
\hline Meat/Fish/Eggs & 121.44 (74.19) & $88.10(56.7)$ & $102.25(60.82)$ & $124.07(62.2)$ & $148.24(101.9)$ & $177.57(78.08)$ & $155.93(83.15)$ \\
\hline Processed meat & $28.98(35.11)$ & $23.92(28.31)$ & $24.47(30.43)$ & $30.73(32.29)$ & $42.76(60.02)$ & $29.39(30.59)$ & $35.91(41.47)$ \\
\hline Meat imitates & $0.41(4.81)$ & $0.45(5.15)$ & $1.17(7.97)$ & $0.20(3.42)$ & $0.28(3.49)$ & $0.00(0)$ & $0.00(0)$ \\
\hline Offals/Other meat & $3.10(13.19)$ & $0.99(5.57)$ & $1.29(6.97)$ & $2.57(8.76)$ & $4.60(17.35)$ & $7.28(24.56)$ & $35.11(25.47)$ \\
\hline Fish/Seafood & 26.34 (34.69) & $20.49(27.2)$ & $29.10(34.11)$ & $26.46(32.11)$ & $38.72(53.85)$ & $23.67(33.08)$ & $32.03(37.93)$ \\
\hline Eggs & $7.92(16.2)$ & $5.11(11.44)$ & $7.31(15.11)$ & $9.30(16.33)$ & $11.67(24.92)$ & $7.75(15.86)$ & $7.36(14.64)$ \\
\hline Dairy products & $217.2(215.6)$ & $149.4(137.3)$ & $251.0(178.0)$ & $167.3(151.9)$ & $532.8(339.2)$ & $188.1(183.2)$ & $244.3(279.5)$ \\
\hline Milk and fresh dairy products & $181.43(211.3)$ & $121.8(135.0)$ & $212.91(178.4)$ & $131.71(149.4)$ & $480.58(338.3)$ & 152.05 (181.2) & $205.75(275.4)$ \\
\hline Drinks & $1385(721.0)$ & $1299(692.9)$ & $1518(689.2)$ & $1260(681.1)$ & $1652(744.1)$ & $1465(783.9)$ & $1534(866.7)$ \\
\hline Fruit \& vegetable juices & $65.13(131.1)$ & $74.45(138.7)$ & $99.26(161.4)$ & $37.16(77.37)$ & $79.91(160.3)$ & $61.11(139.7)$ & $59.38(115.3)$ \\
\hline Tea/Coffee/Cocoa & 434.20 (377.34) & $364.06(343.7)$ & $497.84(379.7)$ & 382.75 (347.8) & $656.87(422.7)$ & 435.54 (391.9) & $515.31(373.8)$ \\
\hline Soft drinks & $95.30(205.5)$ & $167.89(274.9)$ & 76.99 (199.1) & $68.95(151.4)$ & $43.24(115.0)$ & $93.32(204.5)$ & $64.20(147.7)$ \\
\hline Alcoholic beverages & $147.61(295.0)$ & $167.81(357.4)$ & $118.62(248.8)$ & $128.48(213.4)$ & $94.53(196.8)$ & $230.18(411.2)$ & $188.88(314.1)$ \\
\hline Drinking water & $642.93(544.9)$ & $525.03(471.3)$ & $724.89(546.7)$ & $642.78(550.7)$ & $777.37(614.2)$ & 644.95 (546.9) & $706.35(670.3)$ \\
\hline Miscellaneous & $72.37(58.54)$ & $79.58(63.25)$ & $69.57(56.55)$ & $68.27(54.96)$ & $77.35(59.7)$ & $70.37(59.16)$ & $61.10(48.72)$ \\
\hline Sugar/Confectionaries & $18.06(22.79)$ & $26.73(29.78)$ & $16.63(20.94)$ & 14.85 (17.89) & $13.70(20.89)$ & $15.42(18.75)$ & $17.92(17.38)$ \\
\hline Animal fats & $3.80(8.6)$ & $3.38(7.36)$ & $1.91(5.38)$ & $4.85(9.81)$ & $2.89(9.52)$ & $5.13(9.71)$ & $3.38(6.22)$ \\
\hline Vegetable fats & $11.60(13.93)$ & $9.28(10.89)$ & $13.16(13.57)$ & $11.04(13.52)$ & $20.10(21.14)$ & $8.89(10.72)$ & $13.50(15.57)$ \\
\hline Herbs/Spices/Condiments & $19.23(28.45)$ & $17.09(25.44)$ & $19.79(28.67)$ & $19.39(29.0)$ & $21.47(29.68)$ & $20.58(30.98)$ & $14.64(21.89)$ \\
\hline
\end{tabular}


Snacks/Desserts/Others 19.69 (35.75)

23.10 (36.69)

18.08 (36.06)

18.14 (30.55)

19.19 (40.18)

20.35 (41.64)

11.67 (24.42)

${ }^{1}$ Results are presented as means (standard deviation); statistical tests of differences in means between the clusters, based on ANOVA and chi-square, were 
All foods except drinks; B. Drinks.

A. All foods except drinks

"More-Sustainable" cluster
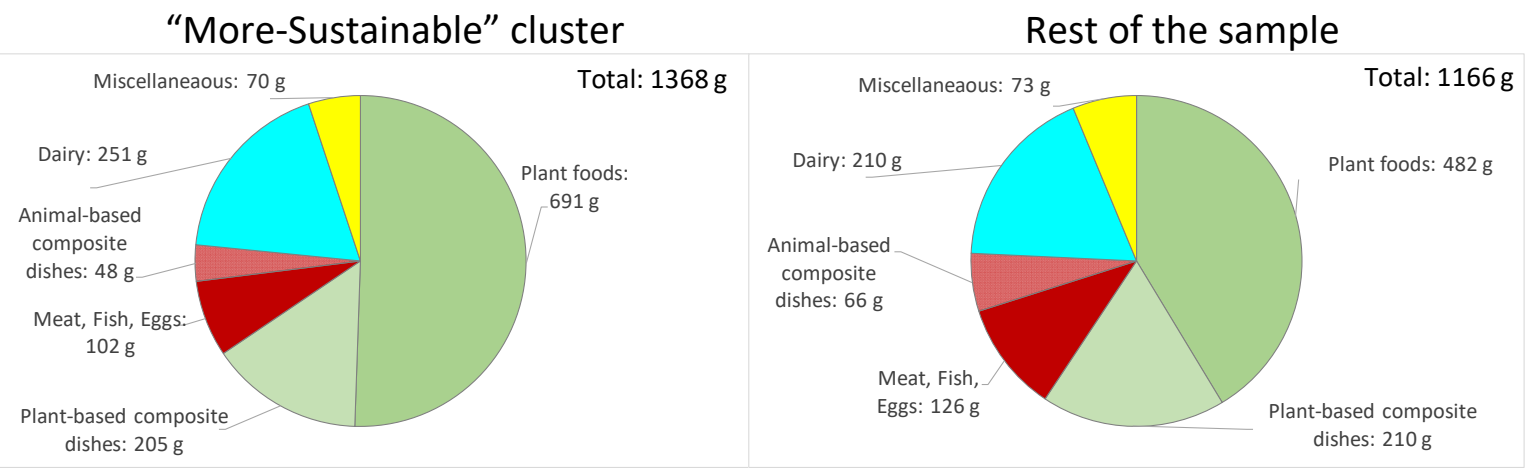

B. Drinks

"More-Sustainable" cluster
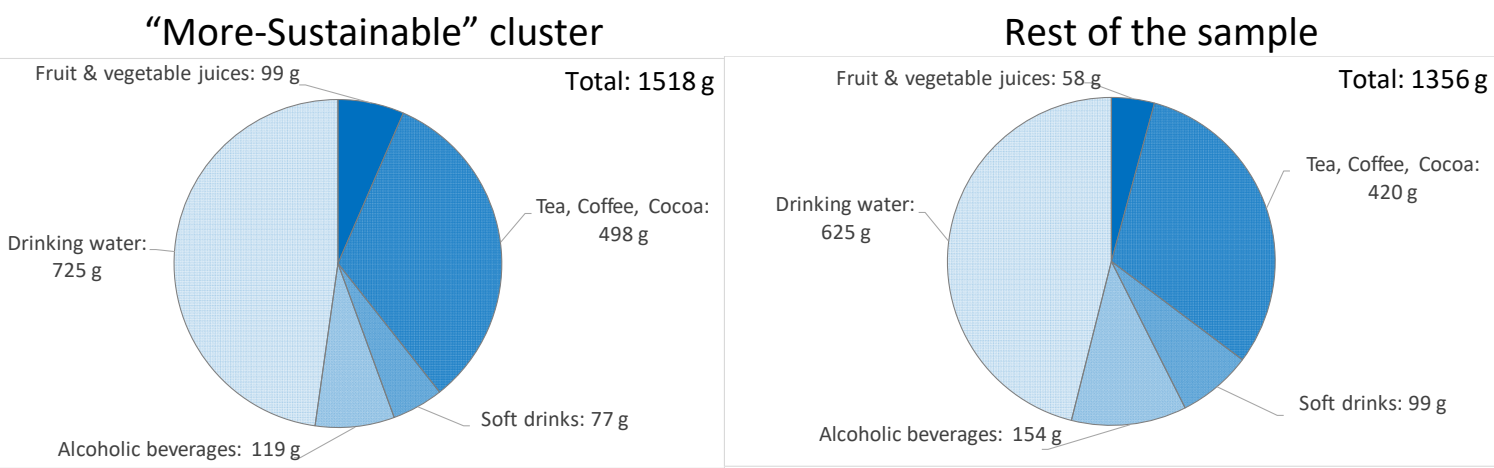

In the classification approach, 1125 diets were identified as "More-Sustainable", 576 of which were also identified with the clustering approach. The "More-Sustainable" class contained a higher percentage of women (69.1\% vs $61.9 \%$ ) and displayed lower dietary GHGE (3485 vs $3834 \mathrm{~g} \mathrm{CO}_{2} \mathrm{eq} / \mathrm{d}$ ) than the "More-Sustainable" cluster (data not shown).

Table 3 shows the average food composition (\% of diet weight) of the individual diets in the "More-Sustainable" cluster and in the rest of the sample as well as p-values indicating statistically significant differences between the two. Corresponding statistics are shown with respect to the "More-Sustainable" class. Compared to the rest of the sample, the "MoreSustainable" cluster was characterized by considerably higher intake of plant foods, slightly higher intake of dairy, lower intake of meats, and lower intake of sugar/confectionaries, soft drinks and alcoholic beverages. Similar results were, with the exception of composite dishes, obtained with the classification approach. The only food sub-group for which the two approaches result in a difference in the internal comparison (i.e. between "More-Sustainable" class/cluster vs rest of sample) is plant-based composite dishes. In the clustering approach, 
both animal- and plant-based composite dishes were lower in the "More-Sustainable" cluster

323 resulting in a statically significant lower share of total composite dishes in this cluster than in

324 the rest of the sample. In the classification approach, however, the "More-Sustainable" class

325 had a larger share of plant-based and a smaller share of animal-based composite dishes

326 compared to the rest of the sample. As a result the share of total composite dishes was not

327 statistically different between the class and the rest of the sample.

Table 3. Contribution (\%) of food groups and sub-groups to total diet weight in the "More-sustainable" cluster ${ }^{1}$ and in the "More-sustainable" class ${ }^{2}$ compared with the corresponding overall rest of the sample

\begin{tabular}{|c|c|c|c|c|c|c|}
\hline \multirow[b]{2}{*}{$\begin{array}{l}\text { Food group \% total } \\
\text { diet weight (sd) }\end{array}$} & \multicolumn{3}{|c|}{ Clustering approach } & \multicolumn{3}{|c|}{ Classification approach } \\
\hline & $\begin{array}{c}\text { "More- } \\
\text { Sustainable " } \\
\text { cluster }^{1}\end{array}$ & $\begin{array}{c}\text { Rest of } \\
\text { the sample }\end{array}$ & $\begin{array}{c}P- \\
\text { value }^{3}\end{array}$ & $\begin{array}{c}\text { "More- } \\
\text { Sustainable " } \\
\text { class }^{2}\end{array}$ & $\begin{array}{l}\text { Rest of the } \\
\text { sample }\end{array}$ & $\begin{array}{c}P- \\
\text { value }^{4}\end{array}$ \\
\hline $\mathbf{N}$ & 1498 & 6804 & & 1125 & 7177 & \\
\hline Plant foods & $24.79 \%(8.65)$ & $19.86 \%(7.94)$ & 0.0000 & $25.16 \%(8.12)$ & $20.06 \%(8.1)$ & 0.0000 \\
\hline Grains & $8.15 \%(4.23)$ & $8.50 \%(4.54)$ & 0.2431 & $8.81 \%(4.16)$ & $8.38 \%(4.53)$ & 0.0001 \\
\hline Vegetables & $5.28 \%(4.18)$ & $3.82 \%(3.34)$ & 0.0000 & $5.17 \%(3.85)$ & $3.92 \%(3.48)$ & 0.0000 \\
\hline Starchy roots & $2.01 \%(2.54)$ & $1.98 \%(2.45)$ & 0.1692 & $1.84 \%(2.5)$ & $2.01 \%(2.46)$ & 0.4332 \\
\hline $\begin{array}{l}\text { Legumes/Nuts/ } \\
\text { Oilseeds }\end{array}$ & $0.74 \%(1.24)$ & $0.63 \%(1.16)$ & 0.0017 & $0.67 \%(1.15)$ & $0.65 \%(1.19)$ & 0.4923 \\
\hline Fruits & $8.60 \%(6.47)$ & $4.91 \%(4.67)$ & 0.0000 & $8.68 \%(6)$ & $5.09 \%(4.93)$ & 0.0000 \\
\hline Meat/Fish/Eggs & $3.71 \%(2.26)$ & $5.31 \%(3.27)$ & 0.0000 & $3.92 \%(2.5)$ & $5.19 \%(3.23)$ & 0.0000 \\
\hline Livestock meat & $0.72 \%(0.96)$ & $1.60 \%(1.93)$ & 0.0000 & $0.54 \%(0.85)$ & $1.58 \%(1.9)$ & 0.0000 \\
\hline Poultry & $0.72 \%(1.11)$ & $0.91 \%(1.42)$ & 0.0000 & $0.81 \%(1.25)$ & $0.89 \%(1.39)$ & 0.4355 \\
\hline Processed meat & $0.85 \%(1.02)$ & $1.21 \%(1.35)$ & 0.0000 & $0.83 \%(0.92)$ & $1.20 \%(1.35)$ & 0.0000 \\
\hline Meat imitates & $0.04 \%(0.3)$ & $0.01 \%(0.18)$ & 0.0000 & $0.03 \%(0.24)$ & $0.01 \%(0.2)$ & 0.0016 \\
\hline Offals/Other meat & $0.05 \%(0.28)$ & $0.14 \%(0.57)$ & 0.0000 & $0.05 \%(0.26)$ & $0.13 \%(0.56)$ & 0.0000 \\
\hline Fish/Seafood & $1.08 \%(1.32)$ & $1.10 \%(1.52)$ & 0.1465 & $1.35 \%(1.54)$ & $1.05 \%(1.47)$ & 0.0000 \\
\hline Eggs & $0.26 \%(0.55)$ & $0.33 \%(0.71)$ & 0.0000 & $0.31 \%(0.74)$ & $0.32 \%(0.68)$ & 0.2586 \\
\hline Dairy products & $8.96 \%(6.45)$ & $8.12 \%(7.55)$ & 0.0000 & $8.97 \%(7.09)$ & $8.16 \%(7.41)$ & 0.0016 \\
\hline $\begin{array}{l}\text { Milk and fresh } \\
\text { dairy products }\end{array}$ & $7.62 \%(6.49)$ & $6.67 \%(7.49)$ & 0.0000 & $7.44 \%(7.13)$ & $6.75 \%(7.36)$ & 0.0030 \\
\hline Cheese & $1.03 \%(1.13)$ & $1.36 \%(1.56)$ & 0.0000 & $1.18 \%(1.21)$ & $1.32 \%(1.54)$ & 0.0000 \\
\hline $\begin{array}{l}\text { Milk product } \\
\text { imitates }\end{array}$ & $0.30 \%(1.56)$ & $0.08 \%(0.78)$ & 0.0000 & $0.35 \%(1.71)$ & $0.09 \%(0.79)$ & 0.0000 \\
\hline Composite dishes & $9.35 \%(6.75)$ & $12.09 \%(9.18)$ & 0.0000 & $11.74 \%(8.46)$ & $11.58 \%(8.91)$ & 0.0516 \\
\hline Plant-based & $7.61 \%(6.62)$ & $9.28 \%(8.53)$ & 0.0000 & $9.77 \%(7.89)$ & $8.86 \%(8.3)$ & 0.0001 \\
\hline Animal-based & $1.74 \%(2.23)$ & $2.81 \%(3.36)$ & 0.0000 & $1.97 \%(2.44)$ & $2.72 \%(3.31)$ & 0.0000 \\
\hline Drinks & $50.77 \%$ (12.39) & $51.67 \%(13.5)$ & 0.0067 & $47.97 \%(12.13)$ & $52.06 \%(13.41)$ & 0.0000 \\
\hline Fruit \& vegetable juices & $3.45 \%(5.45)$ & $2.21 \%(4.27)$ & 0.0000 & $2.08 \%(3.42)$ & $2.49 \%(4.68)$ & 0.0609 \\
\hline Tea/Coffee/Cocoa & $16.96 \%(11.82)$ & $16.14 \%(12.52)$ & 0.3159 & $15.42 \%(10.56)$ & $16.42 \%(12.66)$ & 0.0000 \\
\hline Soft drinks & $2.52 \%$ (5.79) & $4.12 \%(8.27)$ & 0.0001 & $1.52 \%(3.7)$ & $4.19 \%(8.31)$ & 0.0000 \\
\hline Alcoholic beverages & $3.78 \%(6.67)$ & $5.59 \%(8.98)$ & 0.0000 & $3.70 \%(5.44)$ & $5.51 \%(9.01)$ & 0.0000 \\
\hline Drinking water & $24.06 \%$ (14.65) & $23.62 \%(15.45)$ & 0.5163 & $25.25 \%(13.49)$ & $23.45 \%(15.56)$ & 0.0030 \\
\hline
\end{tabular}




\begin{tabular}{lcccccc} 
Miscellaneous & $\mathbf{2 . 4 3 \% ( 1 . 9 3 )}$ & $\mathbf{2 . 9 5 \% ( 2 . 3 )}$ & $\mathbf{0 . 0 0 0 0}$ & $\mathbf{2 . 2 4 \% ( 1 . 6 )}$ & $\mathbf{2 . 9 5 \% ( 2 . 3 2 )}$ & $\mathbf{0 . 0 0 0 0}$ \\
$\quad$ Sugar/ & $0.58 \%(0.7)$ & $0.76 \%(0.92)$ & 0.0000 & $0.55 \%(0.58)$ & $0.76 \%(0.92)$ & 0.0000 \\
Confectionaries & $0.06 \%(0.17)$ & $0.17 \%(0.36)$ & 0.0000 & $0.06 \%(0.17)$ & $0.16 \%(0.36)$ & 0.0000 \\
Animal fats & $0.46 \%(0.47)$ & $0.44 \%(0.51)$ & 0.5782 & $0.51 \%(0.5)$ & $0.44 \%(0.5)$ & 0.0026 \\
$\begin{array}{l}\text { Vegetable fats } \\
\text { Herbs/Spices/ }\end{array}$ & $0.68 \%(0.98)$ & $0.76 \%(1.16)$ & 0.1004 & $0.59 \%(0.89)$ & $0.77 \%(1.16)$ & 0.0000 \\
$\begin{array}{l}\text { Condiments } \\
\text { Snacks/Desserts }\end{array}$ & $0.64 \%(1.29)$ & $0.81 \%(1.42)$ & 0.0011 & $0.52 \%(0.95)$ & $0.82 \%(1.45)$ & 0.0000 \\
\hline /Others & &
\end{tabular}

${ }^{1}$ The "More-Sustainable" cluster was obtained by applying agglomerative hierarchical clustering on principal components of energy-adjusted multiple factor analysis with individual nutrient intakes and dietary GHGE as active variables.

2 The "More-Sustainable" class consists of individual diets having simultaneously a Mean Adequacy Ratio above the median, a Mean Excess Ratio below the median and dietary greenhouse gas emissions below the median.

${ }^{3}$ Energy adjusted p-value of difference in means between the "More-Sustainable" cluster and the rest of the sample.

${ }^{4}$ Energy adjusted $p$-value of difference in means between the "More-Sustainable" class and the rest of the sample.

\section{Discussion}

The new clustering method used to identify the relatively more sustainable diets avoids several shortcomings of previous studies, such as working with theoretical diets, adopting preconceived views on the sustainability of specific food choices or adopting one-dimensional approaches to embrace a fundamentally multi-dimensional concept. Examining diets of adults from national food consumption surveys in five European countries (Finland, France, Italy, Sweden, the UK), this study found a cluster of $18 \%$ of diets that were relatively more sustainable because they combined low dietary GHGE (21 \% reduction vs average of all observed diets) and high nutritional quality. All categories of foods were represented in these diets, but compared to the rest of the sample they contained significantly larger quantities of plant-based products and smaller quantities of meat, soft drinks and alcoholic beverages.

Dietary GHGE was found to be strongly and positively associated with livestock meat consumption but negatively associated with the intake of free sugars. That consumption of livestock meat drives the level of GHGE in the diet is well known (Garnett, 2009; Gerber et al., 2013). It is less known that high consumption of free sugars is related to low environmental impact, although evidence of this relation can be found in the literature (Payne et al., 2016). For instance, a study assessing the environmental impact of several dietary scenarios in the UK found that the diet with the lowest dietary GHGE was a vegan diet with a large share of confectionaries and soft drinks (Berners-Lee et al., 2012). Furthermore, the results in this study suggest that dietary GHGE is practically unrelated to the intake of beneficial nutrients such as vitamins, minerals and fiber, thereby confirming results found in previous studies (Vieux et al., 2013a). 
Due to the complicated relationships between different dimensions of sustainability, unidirectional approaches (e.g. splitting one metric, either nutritional or environmental, into quantiles) are not suitable for studying diets. Such approaches explain why most epidemiological studies on the environmental impact of self-selected diets have found a weak correlation, or even a divergence between the nutritional and environmental dimensions (Perignon et al., 2017). For instance, diets from the lowest GHGE quintile in the French Nutrinet cohort of healthy volunteers were neither the diets with the least amount of nonbeneficiary nutrients nor the diets closest to French dietary guidelines (Seconda et al., 2018). In fact, adherence to dietary guidelines is not necessarily associated with a lower environmental impact. The recommended DASH dietary pattern has for example been found to be associated with lower GHGE in the UK (Monsivais et al., 2015) but higher GHGE in the Netherlands (Biesbroek et al., 2017).

Six clusters were identified based on the nutritional and environmental characteristics of the diets. The relatively more sustainable of these clusters was characterized by large amounts of plant-based products and small amounts of animal-based products. Livestock meat and processed meat represented around 300 grams per week in this cluster which is less than the maximum of 500 grams recommended by international bodies (World Cancer Research/American Institute for Cancer Research, 2007). The presence of non-negligible amounts of animal-based foods in the relatively more sustainable diets implies that excluding entire categories of foods is not necessary in order to move towards more sustainable diets. The same conclusion can be drawn from results obtained with the classification approach. The results is also supported by a previous study which found that the diets of omnivores are not always those with the largest environmental impacts, and that some vegetarians and vegans can have diets with even higher impacts (Rosi et al., 2017). Our results suggest that policies intended to improve the sustainability of European diets should promote flexitarian diets, e.g. by reformulating dietary recommendations. The $21 \%$ GHGE reductions in the more sustainable cluster provides a useful reference for the development of sustainable food systems which requires that both demand- and supply-side aspects are considered. In identifying sustainable food choices, multicriteria methods are preferable to unidirectional approaches. An important contribution of the present study was the original method used to identify more sustainable self-selected diets. Whereas MFA has been widely used in epidemiological studies to derive dietary patterns (Bertin et al., 2015; Gazan et al., 2016), 
considering consequences of food consumption (nutrient intakes and GHGE) as input data, rather than food consumptions themselves, is novel. It is worth noting that this approach avoids the use of food categorization, which may differ between countries, in identifying clusters. As some databases include multidimensional information (e.g. nutritional content, contaminants, price, environmental impacts) (Gazan et al., 2018a), the use of MFA, a method designed to study data composed of variables structured in groups, seems adequate. Using nutrient intakes and dietary GHGE as input data, as opposed to intakes of food items or food groups, avoids ex ante assumptions regarding the sustainability of specific foods or diets. The fact that the relatively more sustainable cluster had the largest content of plant-based foods was in accordance with current national food-based dietary guidelines (FAO Departments and Offices, 2017) and most studies on sustainable diets (EUPHA, 2017). On the other hand, it may be surprising that diets in the cluster with lowest dietary GHGE had the lowest nutritional quality (highest SED, $2^{\text {nd }}$ highest MER, and lowest MAR). The reason is that these diets have the largest quantity of energy dense and nutrient poor foods (i.e., Sugar/Confectionaries, Soft drinks, Snacks/Desserts/Others) which have relatively low environmental impacts (Drewnowski et al., 2015; Masset et al., 2015).

This study has some limitations. Using large, representative and multi-cultural samples was valuable but aggregating different dietary surveys into one sample introduced a potential bias due to methodological differences in the data collection (e.g. dietary records based on varying number of days) (European Food Safety Authority, 2011). In order to minimize this potential bias, all variables included in the MFA were centered, scaled and adjusted for total energy intake. In the future it would be interesting to apply country-specific clustering to see if the results would differ from the results obtained in this study. Another limitation was that the cost of diets was not considered. However, previous studies have found that increasing sustainability does not necessarily increase the cost as it implies a lower consumption of meat which is a costly part of the diet (Fischer and Garnett, 2016). That European average GHGE coefficients were used is another limitation of this study. Using coefficients reflecting country averages would be preferable but are unfortunately available only for some food items in some countries. Furthermore, using only one environmental indicator, dietary GHGE, and only one average value per food item, is a simplification as environmental performance is represented by a diversity of highly variable and possibly uncorrelated metrics (Poore and Nemecek, 2018; Ridoutt et al., 2017). 


\section{Conclusion}

427 As data on the multiple metrics needed to address the sustainability of diet is becoming increasingly available (Gazan et al., 2018a; Johnston et al., 2014), multicriteria analyses such as the multiple factor analysis developed in the present study or more complex mathematical optimization models (Gazan et al., 2018b; van Dooren, 2018) are becoming ever more relevant. In particular, we think that the novel clustering method suggested in this paper would benefit from being generalized and that the results can be used to promote more sustainable dietary patterns adapted to specific populations. Recommendations originating from the actual preferences and choices of consumers have a greater potential to be adopted by consumers than is currently the case. The diets identified with this method can inform policy makers when specifying more sustainable dietary recommendations.

Using a multidimensional approach to identify self-selected diets with the best compromise between environmental and nutritional objectives, the present study suggests that diets with moderate amounts of animal-based products in the short-run is the most realistic path towards more sustainable diets, as it is already adopted by nearly one in five adults in Europe.

Acknowledgements: We thank all of the participants of the European dietary surveys used in this work, as well as the agencies that funded these surveys: National Institute for Health and Welfare in Finland, French Agency for Food, Environmental and Occupational health and safety in France, National Institute for Research on Food and Nutrition in Italy, National Food Administration in Sweden, and Department of Health and Food Standard Agency in the UK.

448 Funding: This study was part of the SUSDIET research project (https://www6.inra.fr/sustainablediets) launched in the framework of the second ERANETSUSFOOD call. The objective was to identify sustainable diets compatible with consumers' preferences in Europe and to analyze how public and private policies can promote sustainable diets. The authors wish to thank the DN Carasso foundation, the French Environment \& Energy Management Agency (ADEME), the Finnish Ministry of Agriculture and Forestry (MMMMakera) and the FORMAS agency for funding the French, Finnish and Swedish components of the SUSDIET project. 


\section{References}

AFSSA, 2009. Etude Individuelle Nationale des Consommations Alimentaires 2 (INCA2).2006-2007.

Aleksandrowicz, L., Green, R., Joy, E.J., Smith, P., Haines, A., 2016. The Impacts of Dietary Change on Greenhouse Gas Emissions, Land Use, Water Use, and Health: A Systematic Review. PLoS.One. 11, e0165797.

Amcoff, E., Edberg, A., Enghardt Barbieri, H., Lindroos, A., Nälsén, C., Pearson, M., Warensjö Lemming, E., 2012. Riskmaten - vuxna 2010-11. Livsmedels- och näringsintag bland vuxna i Sverige [Riksmaten - adults 2010-11. The food and nutrient intake among adults in Sweden]. Uppsala, Sweden.

Baroni, L., Cenci, L., Tettamanti, M., Berati, M., 2007. Evaluating the environmental impact of various dietary patterns combined with different food production systems. Eur. J. Clin. Nutr. 61, 27986. https://doi.org/10.1038/sj.ejcn.1602522

Berners-Lee, M., Hoolohan, C., Cammack, H., Hewitt, C.N.N., 2012. The relative greenhouse gas impacts of realistic dietary choices. Energy Policy 43, 184-190. https://doi.org/10.1016/j.enpol.2011.12.054

Bertin, M., Touvier, M., Dubuisson, C., Dufour, A., Havard, S., Lafay, L., Volatier, J.-L., Lioret, S., 2015. Dietary patterns of French adults: associations with demographic, socio-economic and behavioural factors. J. Hum. Nutr. Diet. https://doi.org/10.1111/jhn.12315

Biesbroek, S., Verschuren, W.M.M., Boer, J.M.A., van de Kamp, M.E., van der Schouw, Y.T., Geelen, A., Looman, M., Temme, E.H.M., 2017. Does a better adherence to dietary guidelines reduce mortality risk and environmental impact in the Dutch sub-cohort of the European Prospective Investigation into Cancer and Nutrition? Br.J Nutr 118, 69-80.

Contreras, P., Murtagh, F., 2015. Handbook of Cluster Analysis-Chapter 6 - Hierarchical clustering, 1st ed, Handbook of Cluster Analysis. Chapman and Hall/CRC, New York. https://doi.org/10.1201/b19706

Cornillon, P.-A., Guyader, A., Husson, F., Jégou, N., Josse, J., Kloareg, M., Matzner-Lober, E., Rouvière, L., 2012. R for Statistics, R for Statistics. CRC Press, Boca Raton. https://doi.org/10.1201/b11828

Donati, M., Menozzi, D., Zighetti, C., Rosi, A., Zinetti, A., Scazzina, F., 2016. Towards a sustainable diet combining economic, environmental and nutritional objectives. Appetite 106, 48-57.

Drewnowski, A., Rehm, C.D., Martin, A., Verger, E.O., Voinnesson, M., Imbert, P., 2015. Energy and nutrient density of foods in relation to their carbon footprint. Am. J. Clin. Nutr. 101, 184-191. https://doi.org/10.3945/ajcn.114.092486

EUPHA, 2017. Healthy and sustainable diets for european countries.

European Food Safety Authority, 2011. Evaluation of the FoodEx, the food classification system applied to the development of the EFSA Comprehensive European Food Consumption Database. Parma. https://doi.org/10.2903/j.efsa.2011.1970

European Food Safety Authority, n.d. Dietary reference values and dietary guidelines [WWW Document]. URL https://www.efsa.europa.eu/en/topics/topic/dietary-reference-values-anddietary-guidelines (accessed 1.24.17).

FAO, 2010. Definition of sustainable diets, in: International Scientif Symposium "Biodiversity and Sustainable Diets United Againts Hunger." FAO Headquarters, Rome.

FAO Departments and Offices, 2017. Food-based dietary guidelines [WWW Document]. URL 
500

501

502

503

504

505

506

507

508

509

510

511

512

513

514

515

516

517

518

519

520

521

522

523

524

525

526

527

528

529

530

531

532

533

534

535

536

537

538

539

540

Fischer, C., Garnett, T., 2016. Plates, pyramids, planet Developments in national healthy and sustainable dietary guidelines: a state of play assessment. FAO \& FCRN.

Fisher, R., 1925. Statistical methods for research workers. Oliver \& Boyd, Edinburgh.

Franklin, S., Thomas, S., Brodeur, M., 2001. Robust multivariate outlier detection using Mahalanobis' distance and modified Stahel-Donoho estimators.

Garnett, T., 2009. Livestock-related greenhouse gas emissions: impacts and options for policy makers. Environ. Sci. Policy 12, 491-503.

Gazan, R., Barré, T., Perignon, M., Maillot, M., Darmon, N., Vieux, F., 2018a. A methodology to compile food metrics related to diet sustainability into a single food database: application to the French case. Food Chem. https://doi.org/10.1016/j.foodchem.2016.11.083

Gazan, R., Béchaux, C., Crépet, A., Sirot, V., Drouillet-Pinard, P., Dubuisson, C., Havard, S., 2016. Dietary patterns in the French adult population: a study from the second French national crosssectional dietary survey (INCA2) (2006-2007). Br. J. Nutr. 1-16. https://doi.org/10.1017/S0007114516001549

Gazan, R., Brouzes, C., Vieux, F., Maillot, M., Lluch, A., Darmon, N., 2018b. Mathematical optimization to explore tomorrow's sustainable diets: a narrative review. Adv. Nutr.

Gerber, P.J., Steinfeld, H., Henderson, B., Mottet, a., Opio, C., Dijkman, J., Falculli, a., Tempio, G., 2013. Tackling Climate Change Through Livestock: A Global Assessment of Emissions and Mitigation Opportunities, Food and Agriculture Organization of the United Nations. https://doi.org/10.1016/j.anifeedsci.2011.04.074

Green, R., Milner, J., Dangour, A.D., Haines, A., Chalabi, Z., Markandya, A., Spadaro, J., Wilkinson, P., 2015. The potential to reduce greenhouse gas emissions in the UK through healthy and realistic dietary change. Clim. Change 129, 253-265. https://doi.org/10.1007/s10584-015-1329-y

Hartikainen, H., Pulkkinen, H., 2016. Summary of the chosen methodologies and practices to produce GHGE-estimates for an average European diet. Helsinki, Finland.

Helldan, A., Kosonen, M., Tapanainen, H., 2013. The National FINDIET 2012 Survey. Helsinki, Finland.

Horgan, G.W., Perrin, A., Whybrow, S., Macdiarmid, J.I., 2016. Achieving dietary recommendations and reducing greenhouse gas emissions: modelling diets to minimise the change from current intakes. Int. J. Behav. Nutr. Phys. Act. 13, 46. https://doi.org/10.1186/s12966-016-0370-1

Irz, X., Leroy, P., Réquillart, V., Soler, L.-G., 2016. Welfare and sustainability effects of dietary recommendations. Ecol. Econ. 130, 139-155. https://doi.org/10.1016/j.ecolecon.2016.06.025

Johnston, J.L., Fanzo, J.C., Cogill, B., 2014. Understanding sustainable diets: a descriptive analysis of the determinants and processes that influence diets and their impact on health, food security, and environmental sustainability. Adv. Nutr. 5, 418-29. https://doi.org/10.3945/an.113.005553

Kim, B.F., Santo, R.E., Scatterday, A.P., Fry, J.P., Synk, C.M., Cebron, S.R., Mekonnen, M.M., Hoekstra, A.Y., de Pee, S., Bloem, M.W., Neff, R.A., Nachman, K.E., 2019. Country-specific dietary shifts to mitigate climate and water crises. Glob. Environ. Chang. 101926. https://doi.org/10.1016/J.GLOENVCHA.2019.05.010

Leclercq, C., Arcella, D., Piccinelli, R., Sette, S., Le Donne, C., Turrini, A., 2009. The Italian National Food Consumption Survey INRAN-SCAI 2005-06: main results in terms of food consumption. Public Health Nutr. 12, 2504-2532. 
Ledikwe, J.H., Blanck, H.M., Kettel Khan, L., Serdula, M.K., Seymour, J.D., Tohill, B.C., Rolls, B.J., 2006. Dietary energy density is associated with energy intake and weight status in US adults. Am. J. Clin. Nutr. 83, 1362-8.

Lluch, A., Maillot, M., Gazan, R., Vieux, F., Delaere, F., Vaudaine, S., Darmon, N., 2017. Individual Diet Modeling Shows How to Balance the Diet of French Adults with or without Excessive Free Sugar Intakes. Nutrients 9, 162. https://doi.org/10.3390/nu9020162

Macdiarmid, J.I., Kyle, J., Horgan, G.W., Loe, J., Fyfe, C., Johnstone, A., McNeill, G., 2012a. Sustainable diets for the future: can we contribute to reducing greenhouse gas emissions by eating a healthy diet? Am. J. Clin. Nutr. 96, 632-9. https://doi.org/10.3945/ajcn.112.038729

Macdiarmid, J.I., Kyle, J., Horgan, G.W., Loe, J., Fyfe, C., Johnstone, A., McNeill, G., 2012b. Sustainable diets for the future: can we contribute to reducing greenhouse gas emissions by eating a healthy diet? Am. J. Clin. Nutr. 96, 632-9. https://doi.org/10.3945/ajcn.112.038729

Masset, G., Soler, L.-G., Vieux, F., Darmon, N., 2014a. Identifying Sustainable Foods: The Relationship between Environmental Impact, Nutritional Quality, and Prices of Foods Representative of the French Diet. J. Acad. Nutr. Diet. https://doi.org/10.1016/j.jand.2014.02.002

Masset, G., Vieux, F., Darmon, N., 2015. Which functional unit to identify sustainable foods? Public Health Nutr. 18, 2488-2497. https://doi.org/10.1017/S1368980015000579

Masset, G., Vieux, F., Verger, E.O., Soler, L.-G., Touazi, D., Darmon, N., 2014b. Reducing energy intake and energy density for a sustainable diet: a study based on self-selected diets in French adults. Am. J. Clin. Nutr. ajcn.113.077958-. https://doi.org/10.3945/ajcn.113.077958

Mertens, E., van't Veer, P., Hiddink, G.J., Steijns, J.M., Kuijsten, A., 2017. Operationalising the health aspects of sustainable diets: a review. Public Health Nutr. 20, 739-757. https://doi.org/10.1017/S1368980016002664

Monsivais, P., Scarborough, P., Lloyd, T., Mizdrak, A., Luben, R., Mulligan, A.A., Wareham, N.J., Woodcock, J., 2015. Greater accordance with the Dietary Approaches to Stop Hypertension dietary pattern is associated with lower diet-related greenhouse gas production but higher dietary costs in the United Kingdom. Am. J. Clin. Nutr. 102, 138-45. https://doi.org/10.3945/ajcn.114.090639

NatCen Social Research, MRC Human Nutrition Research, University College London. Medical School, 2015. National Diet and Nutrition Survey 1-4, 2008/09-2011/12. 7th Edition.

Nelson, M.E., Hamm, M.W., Hu, F.B., Abrams, S.A., Griffin, T.S., 2016. Alignment of Healthy Dietary Patterns and Environmental Sustainability: A Systematic Review. Adv. Nutr. An Int. Rev. J. 7, 1005-1025. https://doi.org/10.3945/an.116.012567

Payne, C.L., Scarborough, P., Cobiac, L., 2016. Do low-carbon-emission diets lead to higher nutritional quality and positive health outcomes? A systematic review of the literature. Public Heal. Nutr 19, 2654-2661.

Perignon, M., Barré, T., Gazan, R., Amiot, M.-J., Darmon, N., 2016a. The bioavailability of iron, zinc, protein and vitamin $A$ is highly variable in French individual diets: Impact on nutrient inadequacy assessment and relation with the animal-to-plant ratio of diets. Food Chem. https://doi.org/10.1016/j.foodchem.2016.12.070

Perignon, M., Masset, G., Ferrari, G., Barré, T., Vieux, F., Maillot, M., Amiot, M.-J., Darmon, N., $2016 b$. How low can dietary greenhouse gas emissions be reduced without impairing nutritional adequacy, affordability and acceptability of the diet? A modelling study to guide sustainable food choices. Public Health Nutr. 1-13. https://doi.org/10.1017/S1368980016000653 
Perignon, M., Vieux, F., Soler, L.-G., Masset, G., Darmon, N., 2017. Improving diet sustainability through evolution of food choices: review of epidemiological studies on the environmental impact of diets. Nutr. Rev. 75, 2-17. https://doi.org/10.1093/nutrit/nuw043

Poore, J., Nemecek, T., 2018. Reducing food's environmental impacts through producers and consumers. Science 360, 987-992. https://doi.org/10.1126/science.aaq0216

Ridoutt, B.G., Hendrie, G.A., Noakes, M., 2017. Dietary Strategies to Reduce Environmental Impact: A Critical Review of the Evidence Base. Adv. Nutr. 8, 933-946. https://doi.org/10.3945/an.117.016691

Rosi, A., Mena, P., Pellegrini, N., Turroni, S., Neviani, E., Ferrocino, I., Di Cagno, R., Ruini, L., Ciati, R., Angelino, D., Maddock, J., Gobbetti, M., Brighenti, F., Del Rio, D., Scazzina, F., 2017. Environmental impact of omnivorous, ovo-lacto-vegetarian, and vegan diet. Sci.Rep. 7, 6105.

Sáez-Almendros, S., Obrador, B., Bach-Faig, A., Serra-Majem, L., 2013. Environmental footprints of Mediterranean versus Western dietary patterns: beyond the health benefits of the Mediterranean diet. Environ. Health 12, 118. https://doi.org/10.1186/1476-069X-12-118

Saxe, H., Larsen, T.M., Mogensen, L., 2012. The global warming potential of two healthy Nordic diets compared with the average Danish diet. Clim. Change. https://doi.org/10.1007/s10584-0120495-4

Seconda, L., Baudry, J., Allès, B., Boizot-Szantai, C., Soler, L.G., Galan, P., Hercberg, S., Langevin, B., Lairon, D., Pointereau, P., Kesse-Guyot, E., 2018. Comparing nutritional, economic, and environmental performances of diets according to their levels of greenhouse gas emissions. Clim. Change 148, 155-172. https://doi.org/10.1007/s10584-018-2195-1

Seves, S.M., Verkaik-Kloosterman, J., Biesbroek, S., Temme, E.H., 2017. Are more environmentally sustainable diets with less meat and dairy nutritionally adequate? Public Health Nutr. 20, 20502062. https://doi.org/10.1017/S1368980017000763

Sjors, C., Hedenus, F., Sjolander, A., Tillander, A., Balter, K., 2017. Adherence to dietary recommendations for Swedish adults across categories of greenhouse gas emissions from food. Public Heal. Nutr 1-13.

Springmann, M., Wiebe, K., Mason-D'Croz, D., Sulser, T.B., Rayner, M., Scarborough, P., 2018. Health and nutritional aspects of sustainable diet strategies and their association with environmental impacts: a global modelling analysis with country-level detail. Lancet. Planet. Heal. 2, e451e461. https://doi.org/10.1016/S2542-5196(18)30206-7

Temme, E.H.M., van der Voet, H., Thissen, J.T.N.M., Verkaik-Kloosterman, J., van Donkersgoed, G., Nonhebel, S., 2013. Replacement of meat and dairy by plant-derived foods: estimated effects on land use, iron and SFA intakes in young Dutch adult females. Public Health Nutr. 16, 1900-7. https://doi.org/10.1017/S1368980013000232

The French Information Center on Food Quality, 2013. French food composition table Ciqual 2013 [WWW Document].

Tilman, D., Clark, M., 2014. Global diets link environmental sustainability and human health. Nature 515, 518-522. https://doi.org/10.1038/nature13959

Tucker, K.L., 2010. Dietary patterns, approaches, and multicultural perspectiveThis is one of a selection of papers published in the CSCN-CSNS 2009 Conference, entitled Can we identify culture-specific healthful dietary patterns among diverse populations undergoing nutrition. Appl. Physiol. Nutr. Metab. 35, 211-218. https://doi.org/10.1139/H10-010 
Tukker, A., Goldbohm, R.A., De Koning, A., Verheijden, M., Kleijn, R., Wolf, O., Pérez-Domínguez, I., Rueda-Cantuche, J.M., 2011. Environmental impacts of changes to healthier diets in Europe. Ecol. Econ. 70, 1776-1788. https://doi.org/10.1016/j.ecolecon.2011.05.001

van de Kamp, M.E., Seves, S.M., Temme, E.H.M., 2018a. Reducing GHG emissions while improving diet quality: exploring the potential of reduced meat, cheese and alcoholic and soft drinks consumption at specific moments during the day. BMC Public Health 18, 264. https://doi.org/10.1186/s12889-018-5132-3

van de Kamp, M.E., van Dooren, C., Hollander, A., Geurts, M., Brink, E.J., van Rossum, C., Biesbroek, S., de Valk, E., Toxopeus, I.B., Temme, E.H.M., 2018b. Healthy diets with reduced environmental impact? - The greenhouse gas emissions of various diets adhering to the Dutch food based dietary guidelines. Food Res. Int. 104, 14-24. https://doi.org/10.1016/J.FOODRES.2017.06.006

van Dooren, C., 2018. A Review of the Use of Linear Programming to Optimize Diets, Nutritiously, Economically and Environmentally. Front. Nutr. 5, 48. https://doi.org/10.3389/fnut.2018.00048

van Dooren, C., Tyszler, M., Kramer, G., Aiking, H., 2015. Combining Low Price, Low Climate Impact and High Nutritional Value in One Shopping Basket through Diet Optimization by Linear Programming. Sustainability 7, 12837-12855. https://doi.org/10.3390/su70912837

Vieux, F., Darmon, N., Touazi, D., Soler, L.G., 2012. Greenhouse gas emissions of self-selected individual diets in France: Changing the diet structure or consuming less? Ecol. Econ. 75, 91101. https://doi.org/10.1016/j.ecolecon.2012.01.003

Vieux, F., Perignon, M., Gazan, R., Darmon, N., 2018. Dietary changes needed to improve diet sustainability: are they similar across Europe? Eur. J. Clin. Nutr. 1. https://doi.org/10.1038/s41430-017-0080-z

Vieux, F., Soler, L.-G., Touazi, D., Darmon, N., 2013a. High nutritional quality is not associated with low greenhouse gas emissions in self-selected diets of French adults. Am. J. Clin. Nutr. 97, 56983. https://doi.org/10.3945/ajcn.112.035105

Vieux, F., Soler, L.-G., Touazi, D., Darmon, N., 2013b. High nutritional quality is not associated with low greenhouse gas emissions in self-selected diets of French adults. Am. J. Clin. Nutr. 97, 56983. https://doi.org/10.3945/ajcn.112.035105

Wolf, O., Pérez-Domínguez, I., Rueda-Cantuche, J.M., Tukker, A., Kleijn, R., de Koning, A., BauschGoldbohm, S., Verheijden, M., Perez-Dominguez, I., 2011. Do healthy diets in Europe matter to the environment? A quantitative analysis. J. Policy Model. 33, 8-28. https://doi.org/10.1016/j.jpolmod.2010.10.009

World Cancer Research/American Institute for Cancer Research, 2007. Food, Nutrition, Physical Activity, and the Prevention of Cancer: a Global Perspective, AICR. ed. AICR, Washington DC.

World Health Organization, 2003. Diet, nutrition and the prevention of chronic deseases-Report of the joint WHO/FAO expert consultation. WHO, Geneva. 